\title{
The Evolution of Suffering, Epiphenomenalism, and the Phenomena of Life: Evidential Problems for Naturalists
}

\author{
James D. Madden
}

Citation: Madden, James D. 2021.

The Evolution of Suffering,

Epiphenomenalism, and the

Phenomena of Life: Evidential

Problems for Naturalists. Religions 12 : 687. https://doi.org/10.3390/ rel12090687

Academic Editors: Piotr Roszak and Sasa Horvat

Received: 6 August 2021

Accepted: 23 August 2021

Published: 26 August 2021

Publisher's Note: MDPI stays neutra with regard to jurisdictional claims in published maps and institutional affiliations.

Copyright: (c) 2021 by the author Licensee MDPI, Basel, Switzerland. This article is an open access article distributed under the terms and conditions of the Creative Commons Attribution (CC BY) license (https:// creativecommons.org/licenses/by/ $4.0 /)$.
Department of Philosophy, Benedictine College, Atchison, KS 66002, USA; jmadden@benedictine.edu

\begin{abstract}
Paul Draper argues that the central issue in the debate over the problem of suffering is not whether the theist can offer a probable explanation of suffering, but whether theism or naturalism can give a better explanation for the facts regarding the distribution of pain as we find them. He likewise maintains a comparison of relative probabilities considering the facts of suffering; atheological naturalism is to be preferred. This essay proceeds in two phases: (a) It will be argued that mainstream positions in naturalistic philosophy of mind make it difficult to take pain as anything but epiphenomenal and therefore not subject to evolutionary explanation. While the distribution of suffering is a difficulty for the theist, the naturalist has equal difficulty explaining the fact that there is any suffering at all in the first place. Thus, the facts of suffering offer no advantage to the atheist. (b) Phenomenologists suggest that there is an intrinsic connection between animal life, pain, and normativity (including a summum bonum). The mere occurrence of life and normativity are, at least prima facie, more likely on the assumption of theism than atheism, so the theist may have a probabilistic advantage relative to the atheist. Phases (a) and (b) together support the overall conclusion that the facts of pain as we find them in the world (including that there is any pain at all) are at least as great, if not greater, a challenge for the atheist as they are the theist.
\end{abstract}

Keywords: evidential problem of evil; epiphenomenalism; evolution; theism; atheism

\section{The Evidential Atheological Argument and Its Critics}

Attempts to demonstrate atheism based on a supposed incompatibility of evil and the existence of God (an omnipotent, omniscient, and perfectly good creator) have fallen out of favor among analytic philosophers of religion for the last few decades. Instead, recent atheologians have preferred a more modest evidentialist approach, according to which the overall distribution of suffering or the occurrence of particular horrors, though not logically incompatible with the existence of God, amount to strong evidence against his existence. In other words, there are readily available examples of apparently gratuitous suffering, i.e., suffering for which we cannot fathom any justifying good due to its seemingly unjustifiable intensity or ubiquity, and gratuitous suffering is not at all what we would expect to find on the assumption that God exists. While conceding that the distribution and intensity of evil are not strictly proofs of atheism, the evidentialist atheologian nevertheless claims that the undeniable empirical facts regarding apparently gratuitous suffering amount to very strong evidence in favor of non-belief. In other words, in the absence of strong contrary evidence, the evidential atheologian argues that the apparent fact of gratuitous suffering is ample justification for accepting atheism on broadly inductive grounds. We may then summarize the evidential atheologian's case in terms of the following simple argument:

(1) If God exists, then there is no gratuitous suffering.

(2) It is probable that there are a great many instances of gratuitous suffering.

Therefore:

(3) It is probable that God does not exist.

Premise (1) is typically undisputed, and the atheologian claims that we have good reason to accept (2). Given our knowledge of the available goods and their connections 
with suffering, it appears that there are quantities and intensities of suffering that are not connected with any sufficiently valuable justifying good, which is to say that appearances favor the occurrence of a good bit of gratuitous suffering. Since a morally perfect being would not allow such horrors to occur, except for the sake of a justifying good, we may conclude that it is likely that God does not exist based on prevalence of inscrutable suffering in the natural order (Rowe 1979; Howard-Snyder 2008).

Some theists use traditional theodicies to cast doubt on (2). The strategy here is to argue that certain well-known goods are sufficiently valuable and connected to the kind of suffering we find in the actual world so as to offer a reasonable justification for God's allowance of what the atheologian claims to be inscrutable suffering (Swinburne 1998, 2008). Other less ambitious theists eschew theodicy proper in favor of a more modest defense. Using this strategy, the theist points out that there are certain goods within our ken that are valuable enough to justify the horrors the atheologian cites. The theist may, at the same time, admit that we have neither a high degree of certainty that God would pursue such goods, nor are these goods clearly necessarily connected to the facts of suffering in the natural world. Nevertheless, the theist employing a defensive strategy believes a plausible theological story might be told in which God would pursue such goods, and for all we know this story is true. That is, we cannot rule out that God is up to something for the sake of such goods when he allows the distribution and intensity of suffering we find in the actual world (van Ingwagen 1991, 2008). Whether one offers a bold theodicy or a more cautious defense, it would seem that (2) is undercut, because we cannot conclude that it is highly probable that God would be without justifying reasons for what the atheologian claims to be gratuitous sufferings; the atheologian's supposedly inscrutable goods are not really so inscrutable.

However successful theodicies and defenses might be, one of the most powerful objections to (2) does not require that we are aware of any good sufficient to justify God's allowance of suffering. Rather, the skeptical theist argues that God, as omniscient, would know (or very likely would know) of both goods sufficiently valuable to justify the empirical of about suffering and connections between such goods and sufferings that are beyond our meager human ken. Thus, the fact that any a particular horror or overall distribution of suffering is apparently gratuitous in no way increases the probability that it is actually gratuitous, because we would expect (or at least we would not be entirely surprised to find) that God pursues goods beyond our ken. In other words, if God exists, then the human intellect is not a reliable indicator of what actually is or is not a gratuitous instance of suffering, and therefore premise (2) begs the question, i.e., we would only accept such a premise if we had some antecedent reason to believe the conclusion. Another way to put the skeptical theist's position is first to point out that the appearance of gratuitous suffering weighs in favor of (2), only if we would expect that the justifying reasons for all sufferings would be apparent to us. The skeptical theist, however, argues that if God exists, we would not be surprised to find that the justifying reasons for much suffering are beyond our ken. Thus, the appearance of gratuitous suffering is no evidence in favor of (2), at least for the theist or somebody who has not ruled out theism entirely for independent reasons (Wykstra 1984; see also Rowe et al. 2001; Wykstra 2017; Hendricks 2020).

The slightest bit of formalism will be helpful as we move forward with this discussion. Let " $G$ " be the proposition stating theism, " $\mathrm{K}$ " be the proposition regarding the common evidential background shared by atheists and theists alike, and " $\mathrm{P}$ " be the proposition stating the occurrence of suffering we find in the actual world. The key claim of the evidential atheologian is:

(4) $\operatorname{Pr}(\mathrm{P} / \mathrm{G} \& \mathrm{~K})<\operatorname{Pr}(\mathrm{P} / \mathrm{K})$.

The skeptical theist, however, denies that (4) is true, and in fact defends something like the following:

(5) $\operatorname{Pr}(\mathrm{P} / \mathrm{G} \& \mathrm{~K})=\operatorname{Pr}(\mathrm{P} / \mathrm{K})$

That is, the skeptical theist argues that the assumption of theism is an undercutting defeater for the atheologian's evidence for (2). If God exists, then our judgments about what 
is or is not a case of gratuitous suffering are unreliable; supposing that God exists, we just are not good judges on such matters. Thus, the occurrence of suffering, even inscrutable suffering, is of no evidential value for the atheist, i.e., the probability of the given facts of inscrutable suffering are neither more nor less probable on the assumption of theism.

\section{Theism, Naturalism, and the Distribution of Pain}

The debate between evidential atheists and skeptical theists has been active for three decades now, and declarations of stalemate have not been uncommon. Various strategies for breaking the deadlock in favor of either the atheist or the theist have been proposed and defended in detail (Adams 1999; Schellenberg 2000; Davies 2006; Russell 2018; Tooley 2019). We, however, will focus on just one such approach, which begins with the claim that the basic issue has been misconstrued. Paul Draper agrees with the skeptical theist that the standard evidential atheologian's defense of (2) involves a questionable inference "from being no known morally sufficient reasons" for God's permission of certain sufferings to there "probably being no such morally sufficient reasons" (Draper 2008, p. 213). His intention is not to defend skeptical theism, as Draper believes that both sides of the debate "have failed to recognize ... that one cannot determine what facts about evil theism needs to explain or how well it explains them without considering alternatives to theism" (Draper 1989, p. 332). That is, the question is not whether theism is likely or unlikely given the particular facts of suffering we encounter in the actual world, but "whether or not any serious hypothesis that is logically inconsistent with theism explains some significant set of facts about evil or good and evil better than theism does" (Draper 1989, p. 332). Draper's point is, even supposing that theism is improbable given the intensity and distribution of inscrutable suffering we find in the actual world, all may not be lost for the theist. If theism is nevertheless the best available explanation of the facts about suffering, then those facts can hardly be counted as significant evidence against theism. Even if the theist's account of suffering is on equal footing to the atheists, the evidential atheologian's case fails; in that case, all things being equal, both positions would be reasonable. The question is then not whether the facts of suffering are likely under the assumption of theism, but whether the facts of suffering are more or less likely under the assumption of theism than they are under the assumption of other competitor hypotheses.

Draper argues that when compared to its primary competitors as an explanation of the facts of suffering, theism comes out quite badly. Philosophical naturalism, theism's primary alternative, certainly entails what Draper calls the "hypothesis of indifference" (HI): "neither nature nor the condition of sentient beings on earth is the result of benevolent or malevolent actions performed by non-human beings" (Draper 1989, p. 332). Let us once again call the propositions stating theism " $\mathrm{G}$ ", the proposition stating the facts about suffering " $\mathrm{P}$ ", and the proposition stating the shared background knowledge " $\mathrm{K}$ ". Draper then defends the following claim:

(6) $\operatorname{Pr}(\mathrm{P} / \mathrm{HI})$ is much greater than $\operatorname{Pr}(\mathrm{P} / \mathrm{G})$

If Draper is correct, then naturalism (which entails HI) has a much better explanation of the facts of suffering than theism, and therefore we have a strong evidential argument for preferring naturalism to theism.

Draper claims that "it is the biological role played by both pain and pleasure in goaldirected organic systems that renders" (6) true (Draper 1989, p. 334). Part of an organic system (S) is biologically useful, according to Draper, "just in case (i) it causally contributes to one of S's biological goals ..., and (ii) its doing so is not biologically accidental" (Draper 1989, p. 335). He uses the example of the experience had by a cat when it encounters a hot oven as to motivate the biological usefulness of pain. Since a cat reacts quickly to the pain and thereby avoids grave injury (and his memory of this painful experience will make it more likely that he will avoid such injuries in the future), his biological goals of survival and reproduction are furthered. Much of the distribution of pain and pleasure among sentient beings seems to be connected to biological usefulness; sentient organisms seem to find things bad for their survival and reproduction painful (or at least devoid of pleasure) 
and things good for their survival and reproduction pleasurable (or at least devoid of pain). Given that evolution by natural selection is perfectly consistent with HI, it would not be entirely surprising to find that pleasure and pain are mainly distributed along the lines of biological usefulness. Of course, there is a good deal of apparently biologically gratuitous pain (and pleasure) among sentient beings, but this once again is not entirely surprising under the assumption of HI; such evolutionarily inscrutable suffering is just the result "from nature's ... failure to 'fine tune' organic systems", and such fine tuning is not what we would expect given HI (See Draper 1989, pp. 338-39).

Whereas the biological usefulness of pain and pleasure renders the distribution of suffering we find in the actual world plausible given naturalism (HI), it seems that it is far less likely under the assumption of theism. The key, for Draper, is that "pain and pleasure ... have a specific sort of moral significance", namely, "pain is intrinsically bad, and pleasure is intrinsically good" (Draper 2008, p. 215). Since pain is intrinsically bad, a good moral agent will cause or allow a sentient being to suffering pain only inasmuch as she has some morally relevant justifying reason for doing so. Theists claim that a perfectly good moral agent is ultimately responsible for the distribution of pain and pleasure in the actual world, so theism is plausible only inasmuch as God has morally relevant justifying reasons for all of the pain involved in this distribution. Note that the naturalist has no worries in this vicinity, because she does not claim that a moral agent, much less a perfectly good moral agent, is responsible for this distribution. The biological usefulness of pain is insufficient as a morally justifying reason for the distribution of suffering in nature by God. Here, the atheist can readily point out that it is antecedently uncertain that God, an omniscient and omnipotent being, could not obtain all the biological usefulness he could want without pain, and there is still the lingering problem of explaining the pain suffered by sentient beings over and above what is biologically useful (God is not expected to broker unnecessary and morally bad side-effects). Thus, Draper concludes that biological usefulness does not provide God "with a morally sufficient reason for permitting humans and animals to suffer in the ways they do" (Draper 2008, p. 215). The theist then can plausibly claim that the distribution of suffering among sentient beings is the work of God only if the demands of biological success and "some unknown justifying moral goal happen to coincide in such a way that each could be simultaneously satisfied. Such a coincidence is (to say the least) antecedently far from certain" (Draper 2008, p. 215; Crummett 2017). Since this happy accident is at least prima facie highly unlikely and naturalism requires no such coincidence, we have good reason to accept Draper's (6). Draper then concludes that naturalism (HI) is much more likely than theism given the facts of suffering, and we therefore have a strong evidential argument for naturalism.

Of course, theists who develop theodicies and defenses are not without resources to mount replies. For instance, one can point out that there are some known goods that make the coincidence of biological usefulness and God's moral ends not nearly so unlikely as Draper supposes. That is, we might have good reason to believe that, or at least for all we know, some known good does in fact justify God in using pain as a mechanism of biological usefulness in just the manner we find in the actual world (see van Ingwagen 1991, 2008). Draper dismisses the theodicies and defensive strategies by pointing out that "they explain certain facts by making others even more mysterious" (Draper 2008, p. 216). For example, if the theist claims that God (for all we know) allows pain in moral agents as punishment for sin or as an occasion for the development of virtues of character, this makes the suffering of non-moral agents all the more mysterious. Draper's point is that any story the theist tells to justify God's allowance of suffering is going to encounter some complicating factors that will decrease the overall probability of the theistic hypothesis. Thus, neither theodicy nor defense is a promising reply.

The skeptical theist will try to undercut Draper's argument by claiming that we would not expect to be aware of what God's reasons are for allowing sentient beings to suffer pain, so the fact that it seems quite unlikely to us that there are such reasons is no indication that there are actually no such reasons. Draper, however, is not troubled by skeptical theism. 
Notice, as Draper points out, the skeptical theist must admit that an omniscient being would just as likely have access to reasons beyond our ken for preventing suffering as he would have access to reasons beyond our ken for allowing suffering. Thus, the skeptical theist's conjecture makes the facts of suffering neither more nor less likely, and therefore it does nothing to improve the theism's prospects as an explanation of the actual distribution of pains and pleasures. In short, skeptical or otherwise, theism does not fare well as an explanation of the facts of suffering when compared to naturalism (HI).

\section{Epiphenomenalism and the Problem of Pain}

In what follows, no effort will be made to improve theism's intrinsic prospects as an explanation of the distribution of pain in the actual world as we find it. The position taken here is doubtful that anything can be done to help the theist along these lines, and, on this point, Draper is without fault. For the purposes of this argument, the theist may concede that she does not possess a terribly good explanation for the distribution of pleasures and pains among sentient beings; though one should note that there are significantly different lines of thought from what we have considered here to which the theist might appeal (Davies 2006, 2011; McCabe 2010). Draper, however, is wrong regarding theism's prospect as an explanation of the distribution of pain in the actual world relative to naturalism. Specifically, none of the most plausible versions of naturalism offers much of an explanation of the occurrence of pain as such, because in each of these views pain is most plausibly to be taken as epiphenomenal. Draper rightly claims that biological usefulness is the most likely naturalistic explanation of pain and pleasure and that biological usefulness requires that pleasure and pain play causal roles in the behavior of sentient beings. If pain is epiphenomenal, as it seems most naturalists should conclude, then it is not biologically useful, and likewise naturalism leaves the occurrence of pain utterly mysterious. However complicated theodicies and defenses might make the explanation of pain, they are still better explanations than no explanation at all.

Draper's argument is focused on pain inasmuch as it is morally relevant; indeed, in his view, pain is intrinsically bad. One might mean various things by pain, but Draper seems to have mind here pain as a conscious experience. Pain is morally relevant because of how it feels, its qualitative aspect. The issue is then whether naturalism is in a good position to offer an explanation of painful qualia in terms of biological usefulness. Most mainstream naturalists eschew any sort of substance dualism or hylomorphism about sentient beings, so the naturalist's treatment of qualia is most likely to amount one of the following positions:

Eliminativism: there strictly speaking are no such entities as qualia, including pain qualia.

Reductive Physicalism: qualia, including pain qualia, are type-identical to neurophysiological states.

Non-reductive (supervenience) Physicalism: though qualia are not type-identical to neurophysiological states, they supervene on neurophysiological states (certain neurophysiological states necessitate certain qualia, and there can be no difference in qualia without a difference in the neurophysiological base).

Emergent Property Dualism: qualia are sui generis, non-physical properties (they are neither reducible to nor strictly supervenient on neurophysiological states), but they are nevertheless entirely dependent on and exhaustively explained by their neurophysiological base.

Panpsychism: qualia are not reducible to, supervenient on, or sui generus emergent from neurophysiological states; rather, qualitative consciousness is a fundamental, non-derivative feature of the most basic physical entities in the same way that charge and mass are non-derivative features of basic physical entities.

If eliminativism is our naturalist's preferred account of qualia, then there really is no evidential problem of pain for the theist (or anybody else), because there is no need 
to explain what does not exist. The reductive physicalist strictly claims that there are such things as pains, but they turn out to be the very same things as neurophysiological states; to be in a pain just is to be in certain type of neurophysiological state. The status of reductive physicalism is very controversial even among naturalists (Polger 2009), and even more contentious is the sense in which the reductive physicalist can say there really are qualia (Dennett 1990). It is, to say the least, difficult to understand in what sense it can be said that neurophysiological states are the very same thing as certain qualitative states. The reductive physicalist does not claim that there is anything like an extra, qualitative property that neurophysiological states have over and above their straightforward physical properties, which seemingly leaves our intrinsic, some would say undeniable, awareness of qualitative states such as pains out of the final ontological story (see Searle 1992). Thus, we can safely conclude that any naturalist who accepts either eliminativism or reductive physicalism has no better explanation of the distribution of pain in the natural world than does a theist armed even with a far-fetched theodicy, because it is unclear that such a naturalist can accommodate pain qualia at all.

The non-reductive physicalist does not claim that qualitative states are type-identical to neurophysiological states, but she typically claims that every token quale supervenes on a token of some neurophysiological state-type or other. Similarly, take the example of a statue of Gandalf the Grey that arises from clay being in a certain configuration, $\mathrm{C}^{1}$. Certainly, being a statue of Gandalf is not identical to being in $C^{1}$ (other configurations could make for equally good statues of Gandalf). Nevertheless, being in $C^{1}$ necessitates being a statue of Gandalf (in the appropriate context), and something could not fail to be a statue of Gandalf without failing to be in $C^{1}$, so there is nothing wanting for an explanation as to why something is a statue of Gandalf, given that it is clay in $C^{1}$. The relationship between being a statue of Gandalf and being in $C^{1}$ is what is meant by supervenience. Particularly interesting to the physicalist is that, even though these properties are not strictly identical, this token of being a statue of Gandalf does not seem to be anything ontologically over and above this token of being in $C^{1}$. Likewise, the non-reductive physicalist claims that pain quale, though not type-identical to neurophysiological states, supervene on neurophysiological states such that pain quale are explained by neurophysiological states (neurophysiological states necessitate pain quale and there can be no difference in pain quale without a difference in neurophysiological state), and their tokens are nothing over and above tokens of neurophysiological states (Melnyk 2008; Kim 1993a, 1993b, 1995, 2005; Madden 2013, 2017).

The primary problem with supervenience accounts of qualitative states, for our purposes anyway, is that they seem to render qualia causally epiphenomenal. That is, it is unclear that there is anything for the supervenient features to contribute to causal relations that is not already accounted for by the supervenience base. Thus, one must either accept a theoretically extravagant overdetermination thesis or conclude that the supervenient features make no causal contribution. For example, if one were to throw our statue of Gandalf through a window, the shattering of the glass would be accounted for perfectly well by the clay's being-in- $C^{1}$ (which is itself probably causally redundant, given the properties of the microphysical constituents of the clay). There is not any unique causal work left to be done by being-a-statue-of-Gandalf. Overdetermination is not typically taken as good news, though there are philosophers willing to accept it (Merricks 2001; Sider 2003; Kim 2005). Even if pain qualia overdetermine their supposed effects, it is still rather difficult to see how they can be accounted for in terms of biological usefulness. That is, overdetermining pain qualia would be biologically unnecessary, because all their work could just as easily be done by their neurophysiological supervenience base. We are still left with a "Why both?" question to answer, and since the supervenience theorist is apt to take the supervenience base as explanatorily more fundamental, the qualitative aspect is left as a nagging curiosity. The point here is that a supervenience account of pain qualia likely renders them epiphenomenal or causally redundant (Kim 2005, pp. 170-73), and therefore a naturalist who accepts such an account of pain qualia cannot explain them in terms of biological usefulness. 
A supervenience naturalist might reply by pointing out that it may just be the case that pain qualia happen to supervene on biologically useful supervenience bases, even though the pain qualia themselves do no work. We would then have a perfectly good explanation as to why there are useless pain qualia, i.e., they supervene on biologically useful neurophysiological states. In other words, maybe pain qualia explanatorily piggyback on the biological usefulness of their supervenience bases, even though they are biologically useless. The problem, however, is that this seems to be a very curious coincidence. It is quite legitimate to ask why it just so happens that a morally relevant property supervenes on a cluster of biologically useful, though morally irrelevant, properties that pervade nature. Maybe sentient beings are just monumentally unlucky that intrinsically bad qualia supervene uselessly on some of their biologically useful physiological systems, but this hardly approaches an explanation. At least the theist employing a far-fetched theodicy or defense could shed some light on this unhappy coincidence. For all we know, the theist employing a defense might claim that God may have arranged some things such that certain biologically useful physiological structures necessitate pain qualia, because he is punishing all sentient beings for the bad acts of a few. Such a story requires all sorts of probability-diminishing special pleading and promissory note theology, but that still leaves the theist better off than the naturalist relative to the fact that there is pain. A low probability explanation that coheres a broad background theory is better than no explanation at all.

The emergent property dualist typically claims that pain qualia are non-physical inasmuch as they are not identical to or strictly supervenient on their neurophysiological correlates, though they are physical inasmuch as they are causally dependent on and arise nomonologically from their neurophysiological correlates; as Sellars and Meehl put it in a classic paper on emergence, a mental state like pain still "belongs to the spacetime network" (Meehl and Sellars 1956, p. 252; see also Bedau and Humphry 2008). Moreover, emergentists frequently claim that emergent properties can exert a top-down sort of causal influence on their neurophysiological correlates, so the biological usefulness of such properties would be far less surprising (O'Connor 1994, 2000, 2001; Searle 2005). A fairly obvious problem, however, is that the concept of sui generis emergence is itself far from transparent. That is, the idea that non-physical (at least qualitative) entities are somehow caused by the straightforwardly physical entities composing the nervous systems of sentient animals strains credulity, or at least it has the air of an appeal to a brute fact more so than an explanation (Strawson 2008; Moreland 2009; Nagel 1998). The idea here is that the contemporary naturalist typically accepts the "dualist sorting" of classical Cartesian fame, according to which the mental and the physical are categorically distinct ontological realms (Dreyfus and Taylor 2015, pp. 11-16). On the one hand, we have the res extensa, i.e., the entity understood solely in terms of spatial and other quantitative properties; while on the other hand, we have the res cogitans, i.e., the entity bearing only qualitative and otherwise intentional properties. The Cartesian dualist famously has an intractable difficulty in accounting for how there can be causal interactions between these categorically disparate ontological orders. No doubt, even if the mind-body interaction problem does not amount to a decisive refutation, it is difficult enough to affect the overall plausibility of the Cartesian position for the worse. One should wonder, however, then, how plausible the naturalist emergentist position is, given this problem. That is, the notion of the essentially quantitative-spatial somehow causing the essentially qualitative-non-spatial is no less perplexing than Cartesian mind-body interaction; especially since these notions of the "physical" and the "mental" are typically defined in contradistinction. Hans Jonas makes this point as follows:

deprived of the dualistic shelter, lonesome "matter" must now account for mind and thereby lose the unambiguous nature of "mere matter" as once conceived. In other words, its concept is, by this very demand upon it, already reabsorbed into a concept under the name of matter; and this in effects reopens the issue of ontology which materialism claims to have settled. (Jonas 2001, p. 129) 
Emergent property dualism may well then create as many mysteries as it solves, in which case it does not provide naturalism any advantage over theism in explaining the distribution of suffering. Specifically, there certainly may be some mystery as to why the omnipotent, omniscient, and morally perfect God of classical theism would tolerate the distribution of suffering we find in the natural world, but it is not clear that the mystery of how mechanistically construed matter can give rise to beings subject to qualitative states is any less improbable. Indeed, God's allowance of inscrutable suffering does not require any such bridging of categorical gulfs like that which opens between the standard, modern account of the mental and the physical. In short, if the naturalist's best option for accounting for pain is sui generous emergentism, then it is not clear that her position comes out ahead of theism in an overall probability comparison.

Leaving aside the worries over the very notion of sui generis emergence, grave worries remain for the emergentist naturalist. Consider the following remarks from David Chalmers:

People put forward speculation-maybe the function of consciousness is planning or decision-making or integrating information or whatever. But then as soon as such a hypothesis is put forward the questions just gets raised 'Why couldn't that have been done without consciousness? Why couldn't you just have had these brain processes which produced that conclusion with no subjective experience anywhere?' (Chalmers 2006, p. 47)

Chalmers's point is that the emergentist account does nothing to improve over the supervenience account in terms of the causal redundancy of qualia. The problem is that the underlying neurophysiological processes from which qualia supposedly emerge seem to be sufficient for causing biologically useful behavior. It does not matter whether the cat is conscious of the heat emanating from the oven so long as it is caused to avoid grave injury when in the presence of such stimuli, and the unconscious neurophysiological correlates of the pain qualia are apparently sufficient for that task. Suppose upon encountering the extreme heat stimulus from the oven, the cat is in an overall, global neurophysiological state zeta. It seems perfectly plausible that we could predict the cat's "downstream" behavior simply on occurrence of zeta. It is zeta that has the direct causal connection to the immediately subsequent neurophysiological events culminating in the cat's retreat from the oven. Even if zeta has the distinct effect of also causing a state of feeling-a-burn, it is obscure as to what, if any, role this qualitative effect has in the downstream behavioral effects. In any event, if zeta is sufficient for the behavioral outcomes, it is unclear why the qualitative effect arises at all. In short, the supposed downward causation of emergent states on their neurophysiological grounds faces the same worries over causal redundancy as those encountered by supervenience theories. It is, therefore, once again far from clear in what sense pain qualia are at all biologically useful (Nagel 2012).

Finally, some naturalists troubled by the problems facing non-reductive physicalism and emergentism, though still interested in preserving the reality of qualia, have suggested that qualitative consciousness might be among the non-derivative properties of fundamental physical entities, just like charge or mass (Chalmers 1996; Strawson 2008; Nagel 2012). According to these panpsychists, there is no more need to explain why a fundamental particle is conscious (or quasi-conscious) than there is need to explain why it is charged; in both cases, we have hit explanatory rock bottom. There is no explanation for the essential properties of fundamental entities. Not surprisingly, it is doubtful that this proposal will help naturalism relative to theism as an explanation of pain qualia. First, the panpsychist asks us to revise our understanding of physical reality nearly beyond recognition; it requires that the common, mechanistic understanding of nature is globally off-base (Nagel 2012). Is such a proposed revision of the basic naturalist picture any more plausible than a theodicy or defense that would exculpate theism? The correct answer to this question is not obviously affirmative. Moreover, even if one is willing to concedesuch a massive revision of our picture of physical reality, the fact it just so happens that basic physical entities have at least the rudiments of morally significant properties is a very unlikely coincidence. At 
the very least, if moral relevance is written fundamentally into the physical constants of the universe, we would have to strain to take any rigid version of naturalism seriously. Once again, the theist at least could appeal to any one of many standard theological stories explaining why God might do so, all of which are explanatory paupers in their own right (though not completely bankrupt), but relative to a naturalist panpsychist's appeal to brute coincidence, they fair at least as well, if not better.

Certainly, a great many issues in the philosophy of mind have been dealt with here in a cursory fashion, and many of these critical points are addressed by proponents of the positions we have discussed (with varying degrees of success). None of the foregoing is aimed at defending any particular account of qualia, and there is much to be said in favor of the view that the entire "qualia debate" is not in good order (Scruton 2012, pp. 40-43; Scruton 1998, pp. 104-6; Rudde 1998). The point here is only to show that Draper has been too quick in helping himself to (6). Without a doubt, theodicies and defenses create as many problems as they solve for the theists, and Draper's claim that skeptical theism cuts both ways has great traction. The fact, however, that the naturalist's attempts to account for pain qualia in terms of biological usefulness either bank on very controversial views in the philosophy of mind or create intractable mysteries of their own casts serious doubt on the claim that the probability of the distribution of suffering as we find it in the actual world is much greater on the assumption of naturalism than it is on the assumption of theism. While the actual distribution of suffering is difficult to square with theism, its proponents have resources (even if not entirely impressive resources) that can in principle explain why there is suffering, e.g., free will, divine retribution, the work of the devil and his minion, etc. Naturalism, however, might be able to explain why suffering is distributed in its currently ghastly manner, but it seemingly has no resources for explaining why there is suffering at all. Under the basic assumptions of mainstream, naturalist philosophy of mind, it is unclear what evolutionary advantage is conferred by pain (or any qualitative state for that matter), and that is the primary explanatory resource in the naturalist's toolkit. Given that there is a distribution of suffering to be explained, naturalism is on better grounds, but it cannot (at least given the philosophical options currently abroad) explain why there is any such distribution of suffering in the first place. We thus have no good reason to accept an argument for naturalism as the best available explanation for the facts of suffering, as the fact of suffering is among the states of affairs to be given an account. In fact, rather than Draper's (6), we have better grounds for

(7) $\operatorname{Pr}(\mathrm{P} / \mathrm{HI})=\operatorname{Pr}(\mathrm{P} / \mathrm{G})$

That is, as it stands, neither theism nor atheism is on terribly good grounds to explain the distribution of suffering in the world as we find it. The theist, admittedly, has a challenge in explaining the ubiquity of seemingly gratuitous suffering, whereas the atheist seems to have little, if any, resources to explain why there is any suffering at all.

\section{Life, Value, and the Summum Bonum: Phenomenological Problems for the Atheologian}

Thus far, using Draper's position as a representative foil, we can see that on a narrow "point-scoring" basis, the atheist and the theist are on par, at least with respect to their explanatory resources to make sense of the facts of suffering as we find them. On the one hand, there is a bona fide problem for the theist regarding the particular distribution of suffering in the world as it stands, which can be rather neatly explained by an evolutionary naturalist story available to the atheist. On the other hand, the very fact there is suffering (living beings subjected to qualitative states such as pain) is equally mysterious for the atheist availing herself of the standard naturalistic positions in the philosophy of mind. That is all very careful, but now we will indulge a bit of speculation on the phenomenology of life, or the philosophy of nature, that will suggest more substantive advantages to the theist's position with respect to these issues.

Has Jonas argues that one of the most revealing marks of life, in contrast to non-living being, is that "life by its nature faces forward and outward at once" (Jonas 2001, p. 100). 
Living beings have a curious mix of transcendence and dependence with respect to their composing parts: though an organism is necessarily composed of some set of parts or other, it is never identical to any one set of parts. For example, Fluffy the cat is not identical to the particles or even grosser parts that compose him (he can gain or lose many of them while maintaining his identity as this individual cat), but, like any organism, Fluffy, as a material being, must be composed of some set of parts in order to exist. The metabolic nature of living things, their constant exchange of components with their environment, is what marks them off from the rest of material being. As Fluffy is a living being, it is necessary that he be composed of some set of parts or other, but which set exactly varies over time.

Jonas observes in this light that organisms "face outward" in the sense that they must be oriented spatially beyond their boundaries to obtain nutrients in the external world, and they also "face forward" in the sense that they must be oriented temporally beyond their present state in the pursuit of these nutrients and to continue to the process of development. In other words, living things have an orientation to spatial externality and the future:

The transitory relation of organic form to its matter distends from the beginning two "horizons" "into" which life continually transcends itself: internally that of time as the next impending phase of its own being toward which it moves; externally that of space, as the locus of the co-present "other" on which it depends for its very continuation. (Jonas 2001, p. 100)

Thus, organisms, because they are not identical to their parts, are always in a state of directed transition; absolute stability in material identity is death and undirected change is injury, so to be alive is to be on the move toward (spatially and temporally) the functional incorporation of externalities. Living things are always oriented toward alterity in their constant need for self-maintenance, which is to say "openness to the world is basic to life" (Jonas 2001, p. 99). It is impossible to describe life without availing ourselves to such terms as "orientation" and "openness", which themselves have unavoidable intentional connotations. Thus, for Jonas, the spatial-temporal orientation of the teleological character of metabolism shows that consciousness is pre-figured in the very rudiments of living being, which certainly is not entirely comfortable for a naturalist (Jonas 2001, pp. 128-34; see also Nagel 2012).

With the emergence of not just life, but animal life capable of the long-range pursuit of needed alterity, e.g., the pursuit of prey or the avoidance of predators, comes "not only developed motor and sensor faculties but also distinct powers of emotion" (Jonas 2001, p. 101). That is, on Jonas's account, there is an intrinsic relationship between distinctively animal life (itself marked by the ability to pursue spatially and temporally distant alterity) and qualitative consciousness: "The appearance of directed long-range motility ... thus signifies the emergence of emotional life. Greed is at the bottom of the chase, fear at the bottom of flight" (Jonas 2001, p. 101). The possibility of the pursuit of a long-range goal presupposes something internal to the pursuant animal keeping it on target, which is partly taken up (along with increased sensory powers) by sentience, i.e., the felt gap between desire internal to the organism and the external object of the desire. In other words, there is an intrinsic link between qualia and animal life. An essential difference between the merely living and the animal is the movement from implicit consciousness or orientation toward alterity to the felt need for the external object. To be an animal is necessarily to be a subject of qualia. To deny that there are qualia or to claim that qualia are ephemeral epiphenomena is all well and good, but Jonas would point out with good reason that such moves are essentially to deny that there are animals or to ignore that animal life has causal traction in the world. One can be forgiven for balking at a metaphysics so austere as to exclude those seemingly obvious phenomena. At the very least, for the purposes of our discussion, any position that would require us to give up such observations would suffer injury to its overall plausibility.

The point to emphasize is that any reasonable phenomenology of life must include pleasure and pain as essential aspects of living being, especially for animal life: 
Responding to the lure of the prey, of which perception has given notice, alertness turns into the strain of pursuit and into the gratification of fulfillment: but it also knows the pang of hunger, the agony of fear, the anguished strain of flight. Pursuit itself may end in the disappointment of failure. In short, the indirectness of animal existence holds in its wakefulness the twin possibilities of enjoyment and suffering, both wedded to effort. The two evolve together, and the liability to suffering is not a shortcoming which detracts from the faculty of enjoyment, but its necessary compliment. (Jonas 2001, p. 105)

To be alive, then, is, in some sense, to be conscious (oriented to alterity), and in the animal, this consciousness carries with it essentially qualitative aspects of both pleasure and pain, which can only be inter-defined and constituted. In other words, there cannot be animals, on Jonas's reckoning, that are not subjects of pain and pleasure. Once again, one might deny that there is such a qualitative state as pain or that pain makes any causal difference, but that is to ignore the plain phenomenal fact of the reality and efficacy of animals.

Phenomenological approaches to life likewise emphasize not just the irreducible psycho-qualitative character of life (especially animal life), but also its value-laden character. Merleau-Ponty observes that the description of living things is impossible without terms implying value: "Already the mere presence of a living being transforms the physical world, makes 'food' appear over here and a 'hiding place' over there, and gives to 'stimuli' a sense that they did not have" (Merleau-Ponty 2012, p. 195). That is, a world in which living things can emerge or evolve (or otherwise arrive on the scene) is a place wherein normativity likewise arises: "Biological autonomy thus necessarily includes the bringing about of norms" (Thompson 2007, p. 158) as beings transcendent to but dependent on their composing parts are subject to benefit or harm, success or failure, good or evil. Evaluative standards, at least taken as the standard of flourishing for a certain natural kind, are intrinsic to the very phenomenon of life, and therefore a world in which life can occur cannot itself be utterly indifferent to values. That is not to say that the world cares about its living denizens, but only that a world in which life can occur is a place where valid normative claims can be made. Life, which transforms the environment into "a place of valence, of attraction and repulsion, approach or escape", entails "a process of sensemaking, of bringing forth of significance and value" (Thompson 2007, p. 74). One may deny normativity as an objective fact following on the being of living things, but that, once again, is to fail to take seriously some of the most salient phenomena of what it is to be a living thing.

Jonas suggests, though without necessarily committing himself to the suggestion, the admission of value into the universe with the emergence of life may further necessitate the notion of a summum bonum, a highest good:

Without the concept of good, one cannot even begin to approach the subject of behavior. Whether individual or social, intentional action is directed toward a good. According to some, the scale of lesser and greater goods that become objects of desire, and thus motivate behavior, culminates in a highest good, the summum bonum. (Jonas 2001, p. 127; see also Jonas 1996, pp. 59-74, 99-114)

From Plato's original arguments for the Forms or Ideas to at least Aquinas's Fourth Way (and likely far beyond that), much of the Western philosophical tradition claims comparisons of better or worse entail an ultimate best. That is, relative normativity presupposes absolute normativity. Of course, many thinkers today would argue that such a principle is at best an optional premise, and, following Jonas, there is no need to commit ourselves to it here, let alone do anything to motivate it. Jonas, however, does note that the fact that life entails relative or more-or-less normativity suggests that there is an absolute normativity. In other words, the relative normativity of life renders plausible or leaves us unable to rule out an absolute normativity. The fact that the natural course of things in the universe even suggests an absolute good does not sit well with the supposition of atheism. The 
universe seems to be a place where a summum bonum might be operative, even if nothing we encounter necessitates The Good as such. At the very least, if we take the phenomenon of life seriously, for all we know there is an absolute best toward which living things move, and our inability to rule out a metaphysically significant hypothesis is not without evidential weight (Menssen and Sullivan 2007).

These phenomenological reflections have taken us a bit far afield from the issues at the forefront in our earlier discussions. Suppose, however, that Jonas' description of life does capture the phenomena in their essence (and certainly little has been done to motivate that claim in the foregoing). It is then the case that there can be no life, at least animal life, without pain and suffering; dissatisfaction is intrinsically related to animality. Indeed, we would even expect there is a wide distribution of pain and suffering among living things; that is "quite simply, the price we pay for consciousness" (Scruton 2012, p. 39). That is not to say we can justify any seemingly otiose distribution of pain and suffering in particular, but only to say that wherever higher-animal life (or maybe any life at all) arrives, these ills necessarily follow. Consider who between the theist and atheist can provide a better explanation for the fact that there is pain in the universe at all, which is part of explaining the distribution of suffering. If our phenomenological reflections are correct, then this is really the question of who can better explain the occurrence of life in the universe, as life is the most fundamental explanation of pain. On which hypothesis, theism or naturalism, is the occurrence of life, particularly higher-animal life, more likely? Certainly, the theist has some advantage here, inasmuch as she accounts for animal life in terms of the ultimate activities of a living being, the Living God of Western monotheism. We can plausibly expect that there would be living things, even higher-living things, under the assumption of theism. Under the supposition of theism, it is not in the least surprising that there are living beings, even higher-animals. No doubt, the naturalist can do much to explain the occurrence of life through the ample resources of evolution, the tremendous age of the universe, etc., but under an atheistic hypothesis it is hard to say that we would expect there to be in a universe in which life occurs. Draper rightly points out that the atheist is likely better able to explain the fact that life evolves; if atheism is true, we would expect speciation to occur through some natural process or other, and the fact that it is indifferent to the distribution of pleasure and pain is not surprising to the atheist. (Draper 2008). That, however, is not to say atheism explains that there is any life at all very well, and on this point the theist has an advantage. Moreover, the initial occurrence of life might be explicable naturalistically, but that is not to say that it is at all antecedently probable under the assumption of atheism, nor does that show life is as likely under the assumption of atheism as theism. There are also considerations of the meaningfulness and significance of life and suffering that seem to go beyond the explanatory resources available to the atheist, but those issues, albeit important, are outside the focus of our current discussion (Oviedo 2019). Thus, the fact that there is any distribution of pain at all is an evidential advantage to the theist, however slight.

Moreover, following the phenomenology of life we developed above, living things and their qualitative foibles are necessarily connected to normative standards, and that fact suggests (though may not entail or even strongly imply) that there is a summum bonum operative in the universe. At least we cannot rule out the latter in a universe wherein living things come to be. Here, too, we should ask which hypothesis seems more apt to these facts regarding life, theism or atheism? Certainly, the normativity and an orientation of living things to the highest Good is intrinsic to Western monotheism, whereas these are not facts we would expect at all under the assumption of atheism. The latter seems to rule out the notion of a summum bonum, but the universe as is stands does not clearly conform to that ruling. Thus, once again, it seems that the fact that life, including its ghastly economy of pain and mortality, is no liability, and may even provide positive support for theism relative to atheism. Is an atheistic universe one in which we would expect that, for all we know, there is a summum bonum? Kant, at least, famously thought the possibility of a unifying highest good required the positing of a robust form of theism, and this is a point 
made by other thinkers from disparate moral and theological traditions (MacIntyre 2016, pp. 314-15). There then seems to be another advantage, however tentative, to theism in accounting for the facts of living beings under the conditions in which we find them, even if those conditions inherently involve the possibility (and even actual ubiquity) of failure and pain.

Of course, little has been done here to support the phenomenological descriptions of life that undergird this argument, and all these conclusions are tentative and, even in the best-case scenario, merely probabilistic and not decisive. That being said, take these reflections as a suggestion of a path of inquiry for the theist. The answer to the atheolgical challenge ultimately lies not in an analysis of divinity and the proposals for divine justification in the allowance of suffering, but in a renewed philosophy of nature, which takes seriously the most salient phenomena of life. These phenomena, as suggested above, though they are not felicitous, are ultimately more on par with realistic expectations of the theist than the atheist.

Funding: This research received no external funding.

Conflicts of Interest: The author declares no conflict of interest.

\section{References}

Adams, Marilyn McCord. 1999. Horrendous Evils and the Goodness of God. Ithaca: Cornell University Press.

Bedau, Mark, and Paul Humphry, eds. 2008. Emergence: Contemporary Readings in Philosophy and Science. Boston: MIT Press.

Chalmers, David. 1996. The Conscious Mind: In Search of a Fundamental Theory. New York: Oxford University Press.

Chalmers, David. 2006. I'm a Conscious Zombie. In Conversations on Consciousness: What the Best Minds Believe about the Brain, Free Will, and What It Means to Be a Human. Edited by Susan Blackmore. New York: Oxford University Press.

Crummett, Dustin. 2017. The Problem of Evil and the Suffering of Creeping Things. International Journal of the Philosophy of Religoin 82: 71-88. [CrossRef]

Davies, Brian. 2006. The Reality of God and the Problem of Evil. New York: Continuum Press.

Davies, Brian. 2011. Aquinas on Good and Evil. New York: Oxford University Press.

Dennett, Daniel. 1990. Quining Qualia. In Mind and Cognition. Edited by William Lycan. New York: Cambridge University Press, pp. 519-58.

Draper, Paul. 1989. Pleasure and Pain: A Problem for Theists. Nous 23: 331-50. [CrossRef]

Draper, Paul. 2008. Evolution and the Problem of Evil. In Philosophy of Religion: An Anthology, 5th ed. Edited by Louis Pojman and Michael Rea. New York: Wadsworth, pp. 207-19.

Dreyfus, Hubert, and Charles Taylor. 2015. Retrieving Realism. Cambridge: Harvard University Press.

Hendricks, Perry. 2020. Skeptical Theism Unscathed: Why Skeptical Objections to Skeptical Theism Fail. Pacific Philosophical Quarterly 101: 43-73. [CrossRef]

Howard-Snyder, Daniel, ed. 2008. The Evidential Argument from Evil. Indianapolis: Indiana University Press.

Jonas, Hans. 1996. Mortality and Morality: A Search for God After Auschwitz. Evanston: Nortwestern University Press.

Jonas, Hans. 2001. The Phenomenon of Life: Toward a Philosophical Biology. Evanston: Northwestern University Pres.

Kim, Jaegwon. 1993a. Supervenience and Mind. Cambridge: Cambridge University Press.

Kim, Jaegwon. 1993b. The Philosophy of Mind. Boulder: Westview.

Kim, Jaegwon. 1995. Supervenience. In A Companion to the Philosophy of Mind. Edited by Samuel Guttenplan. Cambridge: Blackwell, pp. 575-83.

Kim, Jaegwon. 2005. Physicalism or Something Near Enough. Princeton: Princeton University Press.

MacIntyre, Alasdair. 2016. Ethics in Conflict with Modernity: An Essay on Desire, Practical Reasoning, and Narrative. New York: Cambridge University Press.

Madden, James D. 2013. Mind, Matter, and Nature: A Thomistic Proposal for the Philosophy of Mind. Washington, DC: Catholic University Press of America.

Madden, James D. 2017. Is a Thomistic Theory of Intentionality Physicalist? American Catholic Philosophical Quarterly 91: 1-28. [CrossRef]

McCabe, Herbert. 2010. Good and Evil: In the Theology of St. Thomas Aquinas. London: Continuum.

Meehl, Peter, and Wilfrid Sellars. 1956. The Concept of Emergence. In Minnesota Studies in Philosophy of Science. Edited by Herbert Feigl and Michael Scriven. Minneapolis: University of Minnesota Press, vol. 1, pp. 239-52.

Melnyk, Andrew. 2008. Can Physicalism be Non-reductive? Philosophy Compass 3: 1281-96. [CrossRef]

Menssen, Sandra, and Thomas D. Sullivan. 2007. The Agnostic Inquirer: Revelation from a Philosophical Standpoint. Grand Rapids: Eerdmans Publsihing.

Merleau-Ponty, Maurice. 2012. The Phenomenology of Perception. Translated by Donald Landes. New York: Routledge.

Merricks, Trenton. 2001. Object and Person. New York: Oxford University Press. 
Moreland, James. 2009. The Recalcitrant Imago Dei: Human Persons and the Failure of Naturalism. London: SCM Press.

Nagel, Thomas. 1998. Conceiving the Impossible in the Mind-Body Problem. Philosophy 73: 337-52. [CrossRef]

Nagel, Thomas. 2012. Mind and Cosmos: Why the Materialist Neo-Darwinian Conception of Nature Is Almost Certainly False. New York: Oxford University Press.

O'Connor, Timothy. 1994. Emergent Properties. American Philosophical Quarterly 31: 91-104.

O'Connor, Timothy. 2000. Persons and Causes. New York: Oxford University Press.

O'Connor, Timothy. 2001. Causality, Mind and Free Will. In Soul, Body, and Survival: Essays on the Metaphysics of Human Persons. Edited by Kevin Corcoran. Ithaca: Cornell University Press, pp. 44-58.

Oviedo, Lluis. 2019. Meaning and Religion: Exploring Mutual Implications. Scientia et Fides 7: 25-46. [CrossRef]

Polger, Thomas. 2009. Identity Theories. Philosophy Compass 4: 822-34. [CrossRef]

Rowe, William L. 1979. The Problem of Evil and Some Varieties of Atheism. American Philosophical Quarterly 16: 335-41.

Rowe, William, Michael Bergmann, and Daniel Howard-Snyder. 2001. An Exchange on the Problem of Evil. In God and the Problem of Evil. Edited by William L. Rowe. New York: Blackwell, pp. 124-58.

Rudde, Anthony J. 1998. What It's Like and What's Really Wrong with Physicalism: A Wittgensteinian Perspective. Journal of Consciousness Studies 5: 454-63.

Russell, Bruce. 2018. The Problem of Evil and Some Replies to Important Response. European Journal of Philosophy of Religion 10: 105-31. [CrossRef]

Schellenberg, John L. 2000. Stalemate and Strategy: Rethinking the Evidential Argument from Evil. American Philosophical Quarterly 37: 405-19.

Scruton, Roger. 1998. Art and Imagination: A Study in the Philosophy of Mind. South Bend: St. Augustine Press.

Scruton, Roger. 2012. The Face of God. London: Bloomsbury.

Searle, John. 1992. The Rediscovery of Mind. Cambridge, Mass: MIT Press.

Searle, John. 2005. Mind: A Brief Introdution. New York: Oxford University Press.

Sider, Ted. 2003. What's So Bad about Overdetermination? Philosophy and Phenomenological Research 67: 719-26. [CrossRef]

Strawson, Galen. 2008. Real Materialism and other Essays. New York: Oxford University Press.

Swinburne, Richard. 1998. Providence and the Problem of Evil. New York: Oxford University Press.

Swinburne, Richard. 2008. Some Major Strands of Theodicy. In The Evidential Argument from Evil. Edited by Daniel Howard-Snyder. Indianapolis: Indiana University Press, pp. 30-48.

Thompson, Evan. 2007. Mind and Life: Biology, Phenomenology, and the Sciences of Mind. Cambridge: Harvard University Press.

Tooley, Michael. 2019. The Problem of Evil. London: Cambridge.

van Ingwagen, Peter. 1991. The Problem of Evil, The Problem of Air, and the Problem of Silence. Philosophical Perspectives 5: 135-65. [CrossRef]

van Ingwagen, Peter. 2008. The Problem of Evil. New York: Oxford University Press.

Wykstra, Stephen. 1984. The Humean Obstacle to Evidential Arguments from Suffering: On Avoiding the Evils of "Appearance". International Journal for Philosophy of Religion 16: 73-93. [CrossRef]

Wykstra, Stephen. 2017. Skeptical Theism. In The Cambridge Companion to the Problem of Evil. Edited by Chad Meister and Paul Moser. New York: Cambridge University Press, pp. 85-107. 